\title{
The Effects of Inositol on Polycystic Ovary Syndrome
}

\author{
RAZVAN POPOVICI ${ }^{1}$, ANTONETA DACIA PETROAIE ${ }^{2 *}$, ALEXANDRU CARAULEANU ${ }^{1}$, \\ IRINA ESANU ${ }^{3 *}$, CRINGUTA PARASCHIV ${ }^{3}$, MIHAELA GRIGORE ${ }^{1}$ \\ ${ }^{1}$ Grigore T. Popa, and University of Medicine Pharmacy, Faculty of Medicine, Mother and Child Care Department, 16 \\ Universitatii Str., 700115, Iasi, Romania \\ ${ }^{2}$ Grigore T. Popa, University of Medicine and Pharmacy, Faculty of Medicine, Family Medicine Department, 16 \\ Universitatii Str., 700115, Iasi, Romania \\ ${ }^{3}$ Grigore T. Popa, University of Medicine and Pharmacy, Faculty of Medicine, Internal Medicine Department, 16 \\ Universitatii Str., 700115, Iasi, Romania
}

\begin{abstract}
Polycystic ovary syndrome (PCOS) is the most common endocrine condition in the reproductive period of women. In the last years, significant progress has been made in understanding the etiology and pathophysiological mechanisms of the disease. This multifactorial entity is associated with complex hormonal, infertility and metabolic aspects that require a proper medical approach and a therapeutic strategy. The increased concentration of androgens, ovulation disorders, and polycystic ovarian morphology belong to the classic picture of PCOS. Insulin resistance (IR) and related compensatory hyperinsulinemia in PCOS underlie inositol therapy, known as insulin second messengers. These molecules with insulin-mimetic properties enhance insulin sensitivity, leading to a reduction of glucose and insulin blood levels. Choosing Myo-inositol (MI) and D-chiro-inositol (DCI) as a therapeutic option involves understanding their physiological properties and mechanisms through which they improve insulin resistance. This article focuses on recent data from the literature that supports the effectiveness and safeness of inositol treatment in combating endocrine and metabolic disorders of this syndrome.
\end{abstract}

Keywords:polycystic ovary syndrome, insulin resistance, inositol, Myo-inositol, D-chiro-inositol

\section{Introduction}

Polycystic ovary syndrome (PCOS), also known as Stein-Leventhal syndrome, is a heterogeneous disease that affects $5-15 \%$ of women of fertile age. PCOS is the principal cause of infertility that is due to menstrual and metabolism dysfunction. In 2003, the European Society of Human Reproduction and Embryology and the American Society for Reproductive Medicine in Rotterdam defined the most common and used diagnostic criteria. Two of the following three criteria underlie PCOS diagnosis: 1. chronic anovulation disorder (oligo- or anovulation up to amenorrhea); 2. clinical signs (acne, hirsutism) or biochemical signs of hyperandrogenism; and 3. the presence of polycystic ovaries on ultrasound or the presence of 12 or more follicles with a diameter of $2 \pm 9 \mathrm{~mm}$ in each ovary and/or increased ovarian volume (> $10 \mathrm{~mL})$ [1]. Although the etiopathogenesis of PCOS is not clear yet, insulin resistance appears to play a central role in disease onset. Myo-inositol (MI) and D-chiroinositol (DCI), two of the nine inositol stereoisomers, play an essential physiological function. They can act in a complementary manner on glucose metabolism, being considered insulin-sensitizing agents. Therefore, MI and DCI could be an effective therapy for patients with PCOS, considering the beneficial effects on metabolic and reproductive characteristics. 


\section{Hormonal and metabolic aspects of PCOS}

The etiology of PCOS is complex and still insufficiently elucidated, with numerous theories trying to explain a common etiopathology for the different clinical forms of this syndrome [2]. Often it is impossible to determine precisely which is a cause and which is an effect on PCOS growth. There is theory of a theca cell defect that leads to excessive androgen synthesis and implicitly to the clinical and biochemical picture of the disease. The hypothalamic-pituitary-gonadal (HPG) and hypothalamicpituitary-adrenal (HPA) glands' axes play an essential role in the pathophysiology of PCOS. The high ratio of luteinizing hormone $(\mathrm{LH})$ to follicle-stimulating hormone $(\mathrm{FSH})$ is one of the primary causes. FSH levels are low because of a defect in the late luteal and early follicular phases. The increased pulsatility of hypothalamic gonadotropin-releasing hormone $(\mathrm{GnRH})$ leads to an elevated frequency of LH pulse that stimulates the theca cells to produce excess androgen [3]. The main hormonal changes are related to the increase of plasma concentrations of ovarian and adrenal androgens, as well as of estrogens (mainly estrone) resulting from androgens [4]. Androstenedione and testosterone predominantly come from the ovary, while dehydroepiandrosterone sulfate (DHEAS) from the adrenal gland. The elevation of the free-circulating androgens is caused by the reduced sex hormone-binding globulin (SHBG), knowing that less than 3\% of testosterone normally circulates unbound in serum [5].

In recent years, it has been increasingly discussed the problem of insulin resistance and compensatory hyperinsulinemia that occur in patients with PCOS, regardless of body mass index. It is estimated that $50-70 \%$ of women with this disorder have insulin resistance of varying degrees, while in the general population, its prevalence is between $10 \%-25 \%$ [6]. Insulin resistance, defined as decreased insulin-mediated glucose utilization, could be the first significant marker of metabolic disease in women with PCOS at risk for metabolic syndrome and coronary heart disease [7]. The cause of the insulin resistance observed in sick women is not clear yet, particularly in skinny patients. Still, a post-receptor defect in the fat tissue and skeletal muscles (abnormal phosphorylation of tyrosine kinase) has been suggested to affect the transport of glucose [8]. Insulin stimulates the theca cells of the ovary to produce excessive testosterone, which is responsible for the clinical symptoms of hyperandrogenism (acne, hirsutism, alopecia). Obesity amplifies insulin resistance and is a major risk factor in the pathogenesis of anovulation and hyperandrogenism, while weight loss reduces clinical symptomatology. Starting from this metabolic particularity, two types of PCOS are currently discussed, the classic phenotype, characterized by chronic anovulation and hyperandrogenism and the phenotype with high metabolic risk or "metabolic reproductive syndrome" $[9,10]$.

\section{Inositol properties}

Inositols, organic compounds in the cyclohexane class, contain hydroxyl groups attached to a cyclohexane ring. Depending on the location of the hydroxyl groups, nine inositol stereoisomers are differentiated. Of these, five (myo-, scyllo-, muco-, neo- and d-chiro-inositol) occur naturally, and four (l-chiro-, allo-, epi- and cis-inositol) derive from myo-inositol. The two inositol stereoisomers, myoinositol (MI) and d-chiro-inositol (DCI) are the most biologically and physiologically important. MI is the most common inositol isomer naturally present in foods. It is mainly found in fruits, nuts, seeds, soy, peas, beans, or whole grains [11]. Although the inositol molecule is similar to glucose, it cannot be considered a real nutrient, because it can be synthesized in the human body as well as in prokaryotes and eukaryotes [12].

MI biosynthesis is based on glucose phosphorylation to D-glucose-6-phosphate (G6P) by hexokinase. Then, in the presence of myo-inositol-1L-phosphate synthase (MIPS), G6P is converted to 1-L-myo-inositol-1-phosphate, which is dephosphorylated to free MI by the inositol monophosphatase. The synthesis of endogenous MI occurs primarily in the human kidney, under the control of MIPS. It has been estimated that one human kidney can synthesize approximately $2 \mathrm{~g}$ of inositol per day [13]. In vivo, DCI is synthesized from MI, being the product of epimerizing hydroxyl groups of MI at the third carbon (Figure 1) [14]. Note that myo-inositol is epimerized in position 1 to form L-chiro-inositol [15]. The stereoisomer levels are regulated by an insulin-dependent epimerase, the enzyme that maintains a 
physiological relationship between MI and DCI, which differs from tissue to tissue. The conversion rate is specific to each tissue, depending on the need for each of the two different molecules [16]. A 40:1 ratio (MI / DCI) between these two isomers is considered optimal for almost all tissues.

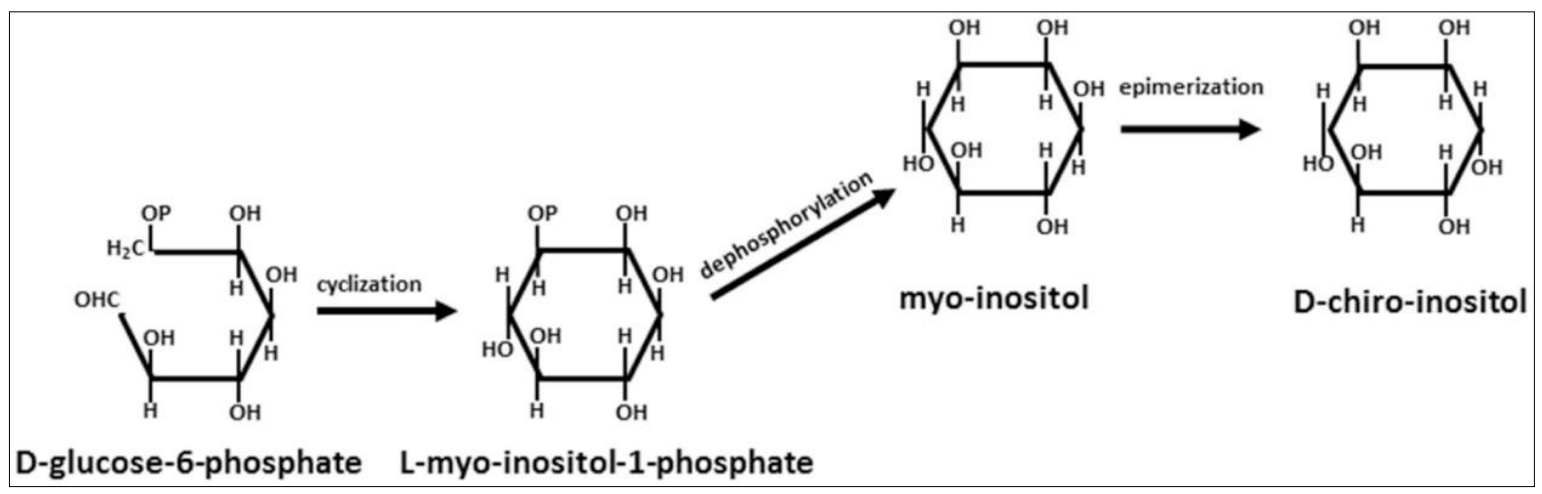

Figure 1. D-glucose-6-phosphate to D-chiro-inositol schematic pathway

Once entered the cell, at the cell membrane level, MI is transformed into phosphatidyl-myoinositol, the precursor of inositol-triphosphate that acts as an intracellular second messenger for insulin, as well as for FSH and TSH. Both MI and DCI play a role in the intracellular transmission of insulin metabolic signals, the two isomers acting synergistically. Their presence inside the cell and the appropriate conversion of DCI from MI by epimerase are significant for the correct oxidative use of glucose and/or its storage as glycogen. Thus, MI and DCI mediate many metabolic actions of insulin, have insulin-mimetic properties, and enhance insulin sensitivity, contributing to lower glucose and insulin blood levels $[17,18]$.

In the ovary, the roles of MI and DCI are well established. MI is involved in FSH signaling, a high concentration of MI being required to achieve a healthy oocyte maturation. Also, by increasing the permeability of the cell membrane to glucose, MI promotes its cellular uptake. On the other hand, DCI mediates insulin-mediated testosterone production and stimulates glycogen synthesis [19]. These activities function in balance in the normal ovary, allowing normal hormonal rates to be preserved and supporting ovarian function.

In PCOS, insulin resistance leads to hyperinsulinemia, which at the ovarian level, triggers changes in inositol metabolism. In an article called "The D-Chiro-Inositol Paradox in the Ovary", it is stated that "PCOS patients with hyperinsulinemia likely present an enhanced MI to DCI epimerization in the ovary; this would result in an increased DCI/MI ratio (i.e. overproduction of DCI), which would in turn would lead to a MI deficiency in the ovary". It showed a 100:1 (MI / DCI ratio) of follicular fluid in healthy women [20], compared to a 0.2:1 (MI / DCI ratio) in PCOS women [21]. Decreased MI reduces the efficiency of MI-mediated FSH signaling and prevents ovulation, the result being poor quality of oocytes [22], supplementation with MI improving their condition [23]. At the same time, ovarian overproduction of DCI stimulates hyperandrogenism and increases plasma testosterone levels [24]. The low serum DCI levels in women with PCOS are due to an increased urinary clearance compared to that of MI that does not change [25]. Body deficiency of chiro-inositol is associated with tissue resistance to insulin action [26].

\section{Experimental part}

Effectiveness and safeness of treatment with MI, DCI or MI/DCI in PCOS

Based on the multitude of metabolic, hormonal, and reproductive disorders that occur in PCOS, treatment must be complex. There are increasing concerns regarding the pharmacological and nonpharmacological therapeutic modalities [27]. Currently, inositols, substances with insulin-like sensitizing effect, are widely used, their role is a subject that has yet to be explored. Administration of 
these is a safe and effective method to prevent and correct PCOS disorders [28]. MI and DCI have been proposed as a possible single or combination therapy, the starting point being their ability to improve insulin resistance [29].

Studies in patients with PCOS have shown that supplementation with MI can improve insulin resistance, reduce hyperandrogenism, regulate menstrual cycles, and increase fertilization rate. No significant side effects were reported after MI use. Mild gastrointestinal secondary effects were observed at high doses of $12 \mathrm{~g} /$ day [30]. In general, the doses of MI used range from 2 to $4 \mathrm{~g} /$ day. The purpose of a controlled clinical study by Artini et al., 2013, which included 50 overweight patients with PCOS, was to evaluate the effects of myo-inositol administration on hormonal parameters. Group A received MYO $2 \mathrm{~g}$ plus folic acid $200 \mathrm{mg}$ daily, while group B folic acid $200 \mathrm{mg}$ daily, both for 12 weeks. Significantly low testosterone and LH and LH / FSH ratios were detected in group A. Insulin sensitivity, expressed as a glucose-to-insulin ratio, and HOMA index significantly improved, and insulin levels decreased. Menstrual cyclicity in all amenorrheic and oligomenorrheic cases was restored. In group B, no changes were detected [31]. A similar study was conducted by Regidor et al., 2018, which included 3602 women with PCOS and who received MI $2 \times 2000 \mathrm{mg}+$ folic acid $2 \times 200$ $\mu \mathrm{g}$ daily. Significant decreases in testosterone and progesterone levels were recorded, from $96.6 \mathrm{ng} /$ $\mathrm{mL}$ to $43.3 \mathrm{ng} / \mathrm{mL}$ and, respectively, from $2.1 \mathrm{ng} / \mathrm{mL}$ to $12.3 \mathrm{ng} / \mathrm{mL}$ ( $\mathrm{p}<0.05$ ), after 12 weeks of treatment. Seventy percent of women had restored ovulation, and 15 percent became pregnant. Twenty-nine PCOS patients underwent IVF protocols for infertility treatment and were prospectively randomized into two groups (placebo / myo-inositol). The results show that in the group treated with myo-inositol results in better fertilization rates and a rising of oocytes quality. At the same time, the number of oocytes recovered in the myo-inositol group was lower, thus reducing the risk of hyperstimulation syndrome in these patients. Thus, myo-inositol could improve IVF protocols for these patients [32].

\section{Results and discussions}

DCI administration has a favorable impact on IR and contributes to the normalization of menstrual cycles in patients with PCOS, too. Some authors report that MI, compared to DCI, acts more efficiently on the metabolic component. A retrospective study published in 2015 by La Marca et al., which included 47 PCOS patients treated with DCI for 15 months at doses of 1-1.5 g/day, highlighted the clinical benefits of this inositol with lowering free testosterone, regulating the menstrual cycle and improving insulin resistance. The percentage of women with regular menstrual cycles increased significantly with the increase in the duration of treatment with DCI (24\% and $51.6 \%$ at an average of 6 and 15 months of treatment, respectively), while the insulin resistance rates decreased significantly during treatment [33]. Pizzo et al., 2014, conducted a study that included 50 patients with PCOS, the purpose being to compare the therapeutic effects of MI, respectively, DCI. Twenty-five received $4 \mathrm{~g}$ of MI plus $400 \mathrm{mcg}$ of folic acid per day, the other $25,1 \mathrm{~g}$ of DCI plus $400 \mu \mathrm{g}$ of folic acid daily, all for six months. The results showed that although both inositols improved ovarian function and metabolic profile, MI mainly acted on the metabolic component, while DCI significantly decreased total testosterone and free testosterone levels [34].

There are increasing concerns about the effectiveness of the combination of MI and DCI [35]. Nordio et al., 2012 compared the effects of the combination of MI plus DCI in doses of $550 \mathrm{mg}$ MI + $13.8 \mathrm{mg}$ DCI (equivalent to $3300 \mathrm{mg} \mathrm{MI}+84 \mathrm{mg}$ DCI in powder format) with that of a dose of $4 \mathrm{~g} \mathrm{MI}$ / day in powder form. After 6 months of treatment, both MI plus DCI and MI showed improvements in the different metabolic markers of PCOS, but combined MI and DCI were twice as effective in reducing HOMA-IR compared to MI alone [36]. Considering the significant changes in the MI / DCI ratio occurring in the ovary in PCOS, the combination of the two inositols was tested, respecting the physiological ratio of 40:1 MI / DCI. Under these conditions, MI and DCI have a synergistic effect, the results being encouraging [37,38]. Nordio et al., 2019, in a clinical trial performed on 56 patients with PCOS who received $2 \mathrm{~g}$ of inositols twice a day for 3 months evaluated the effectiveness of seven 
different MI / DCI ratios: DCI alone, and 1:3.5; 2.5:1; 5:1; 20:1; 40:1, 80:1 MI / DCI ratio. The best data for the restoration of ovulation and the rising of progesterone levels were obtained with 40:1 ratio, followed by 20:1 and 80:1 ratio. Significantly increased values of SHBG and 17-beta-estradiol and significantly lower LH, free testosterone, and basal insulin were found in a 40:1 ratio. Postprandial insulin and HOMA Index decreased in all cases, the FSH level remaining the same in all patients. Therefore, the 40:1 MI / DCI ratio is considered the best at restoring ovulation [39].

\section{Conclusions}

PCOS is a heterogeneous and complex disorder associated with hormonal and metabolic dysfunctions, the etiopathogenesis of which is not yet fully understood. Insulin resistance plays a key role in the mechanism of the disease, as well as in the choice of new treatment strategies. Inositols, the mediators of insulin action, could be a favorable and safe therapeutic tool for patients with PCOS. However, the molecular and cellular levers by which they improve insulin resistance need to be further debated. The two inositol stereoisomers, MI and DCI, bring major benefits to patients with PCOS, acting on both the metabolic and hormonal components, controlling androgen excess, ovarian dysfunction or ovulation, and fertility disorders. It seems that the combinations between MI and DCI have a better therapeutic effect than either alone, although there is no clear answer regarding the optimal MI/DCI ratio and the absolute concentrations of MI and DCI. Compliance with the physiological plasma ratio MI/DCI of 40:1 is accepted by most authors. Given the results so far, we believe that further well-conducted preclinical and clinical studies are needed to obtain more accurate data on the effects of inositols on PCOS.

\section{References}

1.GENAZZANI, A.D., DESPINI, G., SANTAGNI, S., PRATI, S., RATTIGHIERI, E., CHIERCHIA, E.,SIMONCINI, T., Endocrinol. Metab. Synd., 3, no. 3, 2014, p.140.

2.BANASZEWSKA, B., PAWELCZYK, L., SPACZYNSKI, R., Reprod. Biol.,19, no. 4, 2019, p.309. 3.BEDNARSKA, S., SIEJKA, A.,Adv. Clin. Exp. Med., 26, no. 2, 2017, p.359.

4.ROBERT, L., ROSENFIELD, DAVID A., Ehrmann Endocr. Rev., 37, no. 5,2016, p. 467.

5.DE LEO, V., MUSACCHIO, M.C., CAPPElli, V., MASSARO, M.G., MORGANTE, G., PETRAGLIA, F.,Reprod. Biol. Endocrinol., 14, no. 1, 2016, p. 38.

6.***ROTTERDAM ESHRE/ASRM-SPONSORED PCOS CONSENSUS WORKSHOP GROUP, Fertil.Steril., 81, no. 1, 2004, p. 19.

7.TRAUB, M.L.,World J. Diabetes., 2, no. 3, 2011, p. 33.

8.DUNAIF, A.,Endocr. Rev., 18, no. 6, 1997, p. 774.

9.DUNAIF, A., FAUSER, BC.,J. Clin. Endocrinol.Metab., 98, no. 11, 2013, p. 4325.

10.HSU, M.I.,Steroids., 78, no. 8, 2013, p. 761.

11.LARNER, J., BRAUTIGAN, D.L., THORNER, M.O., Mol. Med., 16, no. 11-12, 2010, p. 543.

12.BIZZARRI, M., CARLOMAGNO, G.,Eur. Rev. Med.Pharmacol. Sci.,18, no. 13, 2014, p. 1896.

13.BEEMSTER, P., GROENEN, P., STEEGERS-THEUNISSEN, R., Nutr. Rev., 60, no. 3, 2002, p. 80 .

14.GENAZZANI, A.D.,Reprod. Biomed. Online, 33, no. 6, 2016, p. 770.

15.WOJCIECHOWSKA, A., OSOWSKI, A., JÓŹWIK, M., GÓRECKI, R., RYNKIEWICZ, A., WOJTKIEWICZ, J.,Int. J. Mol. Sci., 20, no. 22, 2019, p. 5787.

16.CARLOMAGNO, G., UNFER, V., ROSEFF, S.,Fertil.Steril., 95, no. 8, 2011, p. 2515.

17.CROZE, M.L., SOULAGE, C.O., Biochimie, 95, no. 10, 2013, p. 1811.

18.MUSCOGIURI, G., PALOMBA, S., LAGANÀ, A.S., ORIO, F., Int. J. Endocrinol., 2016, 2016, p. 6.

19.UNFER, V., PORCARO, G.,Expert. Rev. Clin.Pharmacol., 7, no. 5, 2014, p.623.

20.LAGANa, A.S., GARZON, S., CASARIN. J., FRANCHI, M., GHEZZI, F., Trends Endocrinol.Metab., 29, no. 11, 2018, p. 768. 
21.HEIMARK, D., MCALLISTER, J., LARNER, J., Endocr. J.,61, 2014, p. 111.

22.CHHETRI, D.R., Front.Pharmacol., 10, 2019, p. 1172.

23.SHOWELL, M.G., MACKENZIE-PROCTOR, R., JORDAN, V., HODGSON, R., FARQUHAR, C., Cochrane Database Syst. Rev., 12, no. 12, 2018, CD012378.

24.KALRA, B., KALRA, S., SHARMA, J.B., Indian J. Endocrinol.Metab.,20, no. 5, 2016, p. 720. 25.BAILLARGEON, J. P., DIAMANTI-KANDARAKIS, E. R., OSTLUND, E. JR., APRIDONIDZE, T., IUORNO, M. J., AND NESTLER, J. E., Diabetes Care,29, no. 2, 2006, p. 300.

26.LARNER, J.,Int. J. Exp. Diabetes Res., 3, no. 1, 2002, p. 47.

27.ADVANI, K., BATRA, M., TAJPURIYA, S., GUPTA, R., SARASWAT, A., NAGAR, H.D., et al., J.ObstetGynaecol., 40, no. 1, 2020, p. 96.

28.PKHALADZE, L, BARBAKADZE, L., KVASHILAVA, N.,Int. J. Endocrinol., 2016, 2016:1473612.

29.MORGANTE, G., MASSARO, M.G., DI SABATINO, A., CAPPELLI, V., DE LEO, V.,Gynecol. Endocrinol.,34, no. 1, 2018, p. 4.

30.CARLOMAGNO, G., UNFER, V.,Eur. Rev. Med.Pharmacol. Sci., 15, no. 8, 2011, p. 931.

31.ARTINI, P.G., DI BERARDINO, O.M., PAPINI, F., GENAZZANI. A.D., SIMI, G., RUGGIERO, M., CELA, V.,Gynecol. Endocrinol.,29, no. 4, 2013, p. 375.

32.REGIDOR, P.A., SCHINDLER, A.E., LESOINE, B., DRUCKMAN, R., Horm. Mol. Biol. Clin. Investig.,34, no. 2, 2018.

33.LA MARCA, A., GRISENDI, V., DONDI, G., SIGHINOLFI, G., CIANCI, A.,Gynecol. Endocrinol.,31, no. 1, 2015, p. 52.

34.PIZZO, A., LAGANÀ, A.S., BARBARO, L., Gynecol. Endocrinol., 30, no. 3, 2014, p. 205.

35.SORTINO, M.A., SALOMONE, S., CARRUBA, M.O., DRAGO, F., Front. Pharmacol., 8, 2017, p. 341.

36.NORDIO, M., PROIETTI, E.,Eur. Rev. Med. Pharmacol. Sci.,16, no. 5, 2012, p. 575.

37.BEVILACQUA, A., BIZZARRI, M., Best.Pract. Res. Clin.ObstetGynaecol., 37, 2016, p. 129.

38.LAGANÀ, A.S., GARZON, S., CASARIN, J., FRANCHI, M., GHEZZI, F., Trends Endocrinol.Metab., 29, no. 11, 2018, p. 768.

39.NORDIO, M., BASCIANI, S., CAMAJANI, E., Eur. Rev. Med.Pharmacol. Sci., 23, no. 12, 2019, p. 5512 . 